\title{
Valuation of Benefits of Water Quality and Water Supply to Justify Payments for Ecosystem Services in Mae Sa Watershed, Chiang Mai, Thailand
}

\author{
Oraphan Pradit $^{1 *}$ and Jirawan Kitchaicharoen ${ }^{2}$
}

\begin{abstract}
${ }^{1}$ Agricultural Systems Management Program, Center for Agricultural Resource System Research, Faculty of Agriculture, Chiang Mai University, Chiang Mai 50200, Thailand

${ }^{2}$ Division of Agricultural Economics, Department of Agricultural Economy and Development, Faculty of Agriculture, Chiang Mai University, Chiang Mai 50200, Thailand
\end{abstract}

*Corresponding author. E-mail: mimaggie38@hotmail.com https://doi.org/10.12982/CMUJNS.2020.0042

Received: April 10, 2019

Revised: August 24, 2019

Accepted: October 28, 2019

\begin{abstract}
For the past two decades, the concept of Payments for Ecosystem Services (PES) has been increasingly used as a market-based instrument to support natural resources and environmental management. Economic evaluation of ecosystem services is an important step for implementing a PES scheme as it helps provide information to stakeholders for their decision-making on payment. This paper aims to evaluate the ecosystem services from upstream village conservation activities in Mae Sa watershed in terms of such water ecosystem services as water quality and water supply. The results revealed that the benefits gained from cleaned water and drought prevention due to conservation activities are worth more than the costs. Moreover, these economic values are the partial economic values of ecosystem services in the watershed and will be used as an effective communication tool to raise concerns among stakeholders over the importance of resource conservation and sustainable resource management practices under the implementation of PES scheme in Mae Sa watershed.
\end{abstract}

Keywords: Payments for ecosystem services, Ecosystem services valuation, Damage cost avoided, Choice experiment, Contingent valuation method 


\section{INTRODUCTION}

Water is a resource basic for and connected with a myriad of human activities, and it is vital for the survival of all living beings. While it is referenced in different ways by different disciplines, water is a renewable resource in natural resource economics with a growing prevalence of water shortage and water quality problems in many countries and specific areas. In Northern Thailand, particularly in the hilly watershed areas, a water problem is associated with sediments contamination in water bodies, which affects water consumption and cost of water utilization. In 2000, a land use survey by the Landsat STM program found that 12 million rai of highland forests in the watershed area were destroyed (National Statistical Office, 2005; Tongmee, 2007). It is claimed that deforestation in the north of Thailand has negative impacts on water flow system and increases sedimentation and siltation in reservoirs and watercourses. In addition, the droughts consequential to deforestation had affected the downstream water users (Enter, 1995).

Mae Sa watershed is one basin that has drought effect and water scramble problems because this area has rapidly expanding economic activities involving agriculture, tourism businesses such as resorts, homestays, restaurants, coffee shops, and tourist attractions, government offices and a lot of households. According to a report by the Department of Water Resources (2007), Mae Sa watershed has suffered from water shortages, low-quality water, and water allocation problems (cited by Pramoon, 2008). It also found that many activities in upstream areas used water more than the river capacity. Especially in 2015, a severe drought affected all sectors in Mae Sa watershed. Moreover, households and tourism businesses released wastewater into the river and intensive chemicals were used in agricultural areas without soil and water conservation (Pollution Control Department, 2011). A study of Rungruangwong and Prompati (2007) found that there were 4 from 7 spots that needed to be recovered to the original condition. In terms of chemical water quality, the $\mathrm{pH}$ value was low probably due to wastewater from various activities.

Nowadays, the people who live in upstream areas suffer from environmental problems and are aware that they should conserve the natural resources and environment for the next generations. Annually, the upstream villages have been doing the conservation activities such as check dam building, living weir establishment, fire protection, and forest plantation to improve the ecosystem. Nevertheless, the conservation activities have costs and the downstream people have external benefits from such upstream measures as preventing drought, decreasing sedimentation, slowing down the water flow and water retention. Thus, they should pay or support the upstream villages under payments for ecosystem services scheme like that was implemented in Indonesia (1985) under the lake protection program, and Vietnam (1990) under the reforestation program. PES in Mae Sa was introduced by the United States 
Agency for International Development's: Lowering Emissions in Asia's Forests: USAID - LEAF program in 2011. This is a small project between one water company and one village but most of the stakeholders did not understand this concept and knew more about Corporate Social Responsibility: CSR (USAID LEAF, 2014). In general, PES implementation is about ecosystem service values in terms of money that the service providers make available to all stakeholders to increase the awareness of the beneficiaries to provide some supports in return to the ecosystem service providers.

The principle of PES emphasizes provider-based economic approaches (Mauerhofer, et al. 2013) and focuses on "the beneficiary pays principle". PES will lead to more efficiency of natural resource utilization by economic incentives. It is believed that ecosystem degradation will cause humans to receive fewer benefits from the ecosystem services and will increase the social cost (Wunder, 2007). The people protecting and enhancing the ecosystem service provision will be recognized as ecosystem service providers who make a positive impact on the people living outside the area (beneficiaries) or users of ecosystem services (Steiner et al. 2000). In return, the service users provide the payment to the service providers as incentives to manage their land or natural resources for the purpose of enhancing the ecosystem services. However, the benefit values cannot be clearly described by PES; therefore, the ecosystem service valuation is the information for their decision-making on payment.

This study aims to evaluate the benefits of water by considering the services that occur by changing the water quality and water supply from conservation activities in terms of the economic values of cleaned water and preventing drought. These values were evaluated from water users' willingness to pay for water quality improvement and damage cost of drought. Although these economic values are the partial economic values of ecosystem services in the watershed, it can be used as an effective communication tool to raise concerns among stakeholders over the importance of resource conservation. Consequently, PES can generate sustainable resource management in the watershed.

\section{MATERIALS AND METHODS}

\section{Site of study}

Mae Sa watershed is located in a part of Mae Rim District, Chiang Mai, Thailand. It is a relatively small scale watershed, covering a total area of 142.30 square kilometers or 87,113 rai ( 1 hectare $=6.25$ rai), which can be divided into 4 parts: forest $53,336.81$ rai or $61.23 \%$, agriculture $19,403.44$ rai or $22.27 \%$, residential area 12,906 rai or $14.82 \%$ and others $1,466.44$ rai or $1.68 \%$ (Land Development Department, 2005; Regional Environment Office 1, 2016). The watershed comprises upstream and downstream areas. In the upstream areas, there are several villages where most farmers are living and considered as ecosystem service providers in this study. For the downstream areas, there are 
some farmers, municipality, local entrepreneurs, mineral water company, hotels and resorts which are considered as the service users in Mae Sa watershed.

\section{Conceptual framework}

In Mae Sa watershed, the conservation activities are directly related to three main ecosystem services. In the agricultural ecosystem, the upstream people practice soil conservation by building terraces on sloping land that could reduce the rate of soil erosion and reduce chemical use that could reduce chemical contaminated in water. In the forest ecosystem, the upstream villagers do the conservation activities by fire protection and forest plantation that could improve water quantity and quality. The last in water ecosystem, the upstream villagers do the conservation activities by check dam building and living weir that could reduce water turbidity and drought. These conservation activities are service in regulating services and provisioning services described by change in water quality and quantity (Millennium Ecosystem Assessment, 2005).

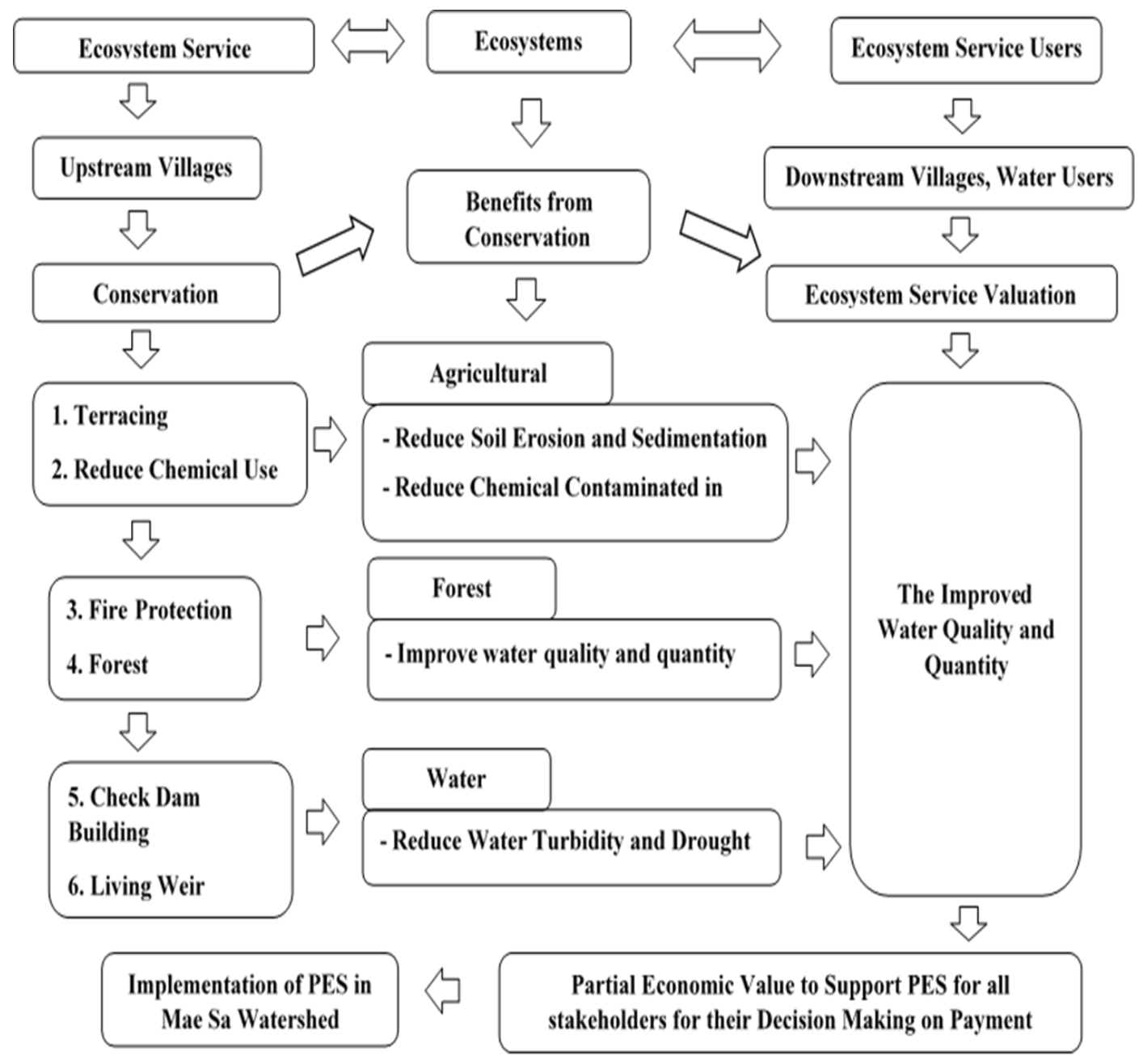

Figure 1. Conceptual framework.

This study intends to assess these benefits in terms of the economic value of cleaned water and the damage cost of drought. The economic evaluation from 
water quality improvement is made by willingness to pay method and the water quality which has many levels is studied using choice experiment method. The assessment of damage cost of drought is made using the damage cost avoided that is adapted from intangible flood damage quantification (Lekuthai and Vongvisessomjai, 2001). These benefits of water quality and quantity valuation can be adapted for all of the water users such as agricultural, households and businesses sectors to make their decision making on payment.

\section{Data collection methods}

Data collection methods were divided into two parts: 1) water users' willingness to pay for water quality improvement by means of focus group discussion, key rider interview, and choice experiment questionnaires, 2) damage cost of drought by means of damage cost questionnaires.

Water users' willingness to pay for water quality improvement. There were 2 levels of data collection; the first was village level data about conservation activities such as materials, labor and total cost collected by interviewing the village leaders. These data were used to design the choices for choice modeling in the questionnaire. The second was water users' level data about their willingness to pay for water quality improvement and factors affecting their willingness to pay.

The number of water users was 19,819 (219 businesses and 19,600 households) (Mae Rim Waterworks Office, 2017). For data collection, quota sampling was used for each population of water users. The total size which was statistically acceptable $(P<0.05)$ was 392 samples (Yamane, 1967). In this study, the number of samples was 454 ( 376 households and 78 businesses).

Damage cost of drought. The total population in Mae Sa watershed consisted of 8,611 households, 3,170 farmers and 219 businesses (Pong Yang and Mae Ram Sub-district Administrative Organization, 2016). The field survey for costs of drought damage was carried out using structured questionnaires. Quota sampling was used for each population sector. The total sample size was 437 samples which comprised 230 households, 129 farmers and 78 businesses. The intensive fieldwork was carried out in the watershed area between August and September 2017.

\section{Valuation methods}

This study implemented two technical approaches including 1) contingent valuation method using choice experiment method by means of allowing people to choose from a menu of options with differing levels of ecosystem services and differing costs (Federal Ministry for Economic Cooperation and Development: BMZ, 2012). Moreover, the specifying relevant attributes in the conditional Logit model and socio-economic factors were used for calculation in Tobit model under the hypothetical situation. 2) Damage cost avoided was used to evaluate the damage cost of drought as in the equations. The value is based on the costs of 
actions taken to avoid damages if a specific ecosystem service did not exist (Federal Ministry for Economic Cooperation and Development: BMZ, 2012). In this study, the procedure was adapted from intangible flood damage quantification (Lekuthai and Vongvisessomjai, 2001).

\section{Choice experiment method}

The attributes and levels of design were used to analyze the suitable activities and value of the willingness to pay for supporting the upstream village conservation activities. The activities consist of reducing the chemical use (to solve the problem of chemicals contamination in the water) and terracing (to solve the problem of soil erosion and sedimentation) in agricultural ecosystem, forest plantation and fire protection (to solve the problem of water quantity and quality) in forest ecosystem and check dam building and living weir establishment (to solve the problem of water turbidity and drought) in water ecosystem.

The hypothetical situation is nowadays there is a group of 'Community based conservation and management of natural resources and the environment in Mae Sa watershed'. The upstream villagers (ecosystem services providers) especially spend more time on conservation activities, leading to the loss of opportunity cost of work and rest because all of them have to obey the community rules to participate in the village activities. These conservation activities require the cost, materials, and labor; therefore, the downstream households, resorts, homestays, restaurants and coffee shops (ecosystem services users) who have the benefits from upstream conservation activities or external benefits such as water quality and quantity should also support these activities for sustainability.

Conservation activities in Mae Sa watershed can be divided into 6 types as follows: Activity 1 chemical use reduction, Activity 2 agricultural land terracing, Activity 3 forest plantation, Activity 4 fire protection, Activity 5 check dam building and Activity 6 living weir establishment. Water quality condition can be divided into 4 levels: 1) Turbid water, sediments all year, chemical contamination, 2) Turbid water, sediments only in rainy season, chemical contamination, 3) Clear water, no sediments, chemical contamination and 4) Clear water, no sediments, slight chemical contamination.

Cost of conservation activities and the possible payment of water users was estimated for each activity 1) Chemical use reduction: the agricultural land in Mae Sa watershed is 7,054 rai. Most of the areas are still farmed with the use of chemicals. However, $40 \%$ of these areas are under the practice of using chemical input at a safe level which will get routine quality check from the Royal Project. Reducing chemical use thus costs 2,185 baht/rai with the total cost in the watershed of 15,412,990 baht or 777.69 baht/household for those households using water in midstream and downstream areas. From the polluters-pay principle, cost of conservation activities, in this case chemical use reduction, has to be responsible partly by the farmers as they used to have a part to make the environmental damage in the past. With this cost, however, both farmers and 
downstream water users will enjoy the benefits of lower exposure to chemicals, lower soil erosion, and more water availability for farming (Nantansen, 2008) . 2) Terracing: total vegetable cultivation area is 3,200 rai. However, $10 \%$ or 320 rai of the vegetable land remains farmed without terracing. The terracing costs 6,952 baht/rai, with the total cost in the watershed of 2,224,640 baht or 112.25 baht/household using water in midstream and downstream areas. 3) Forest plantation: there are 10 villages in upstream areas and they are supposed to plant the forest at least $5 \mathrm{rai} /$ village/year. The forest plantation costs $17,730 \mathrm{baht} / \mathrm{rai}$, with the total cost in the watershed of 886,500 baht or 44.73 baht/household using water in midstream and downstream areas. 4) Fire protection: the upstream villages are supposed to increase the forest fire break strips by $10 \mathrm{~km} / \mathrm{year}$. The fire protection costs $18,735 \mathrm{baht} / \mathrm{km}$, with the total cost in the watershed of $1,873,500$ baht or 94.53 baht/household using water in midstream and downstream areas. 5) Check dam building: the upstream villages are supposed to build the check dam at least 3 units/year. The check dam building costs 7,210 baht/unit, with the total cost in the watershed of 216,300 baht or 10.91 baht/household using water in midstream and downstream areas. 6) Living weir: in 2017, 11 living weirs were built in Mae Sa watershed; thus, in this year at least 10 units should be built. The living weir costs 50,000 baht/unit, with the total cost in the watershed of 500,000 baht or 25.23 baht/household using water in midstream and downstream areas as in Table 1.

Table 1. Attributes and levels.

\begin{tabular}{lll}
\hline Attribute & Description & Level \\
\hline Conservation & Conservation & 5 levels: \\
services & activities that & 1) Activity 4 \\
& should be & 2) Activities 3,4 and 5 \\
& supported in & 3) Activities $3,4,5$ and 6 \\
& terms of & 4) Activities $2,3,4,5$ and 6 \\
& payment. & 5) All activities $1-6$ \\
\hline Water quality & Water quality & 4 levels: \\
& under 4 & 1) Turbid water, sediments all year, chemical \\
& conditions & contamination \\
& & 2) Turbid water, sediments only in rainy season, chemical \\
& & contamination \\
Individual & The amount & 4) Clear water, no sediments, chemical contamination \\
payment per & of payment & 1) 0 \\
year & that should be & 2) 100 baht/year \\
& paid per year. & 3) 150 baht/year \\
& 4) 175 baht/year \\
& & 5) 300 baht/year \\
& & 6) 1,070 baht/year \\
\hline
\end{tabular}


The choice experiment is based on attributes and respondents are asked to make a comparison and choose between environmental alternatives characterized by a variety of attributes and levels of attributes (Holmes and Adamowicz, 2003). The record of the choices among the alternatives is used to estimate the respondents' willingness to pay (WTP) by modeling the probability of the chosen alternative (Stewart and Kahn, 2006; Meyerhoff et al., 2008).

The number of levels in each attribute was analyzed by the full factorial method, giving rise to 120 possible alternatives $\left(5^{*} 4 * 6=120\right)$. However, in each alternative, one attribute level may conflict with the other two attribute levels. Thus, the possible alternatives were reduced by the orthogonal design in the SPSS program. Orthogonality was a feasible alternative and had no conflict in the attribute level of 28 alternatives. However, more alternatives were considered too large for respondents to choose from.

The cyclical design method was implemented to group 8 choice sets. Each choice set was divided into 3 alternatives. Alternative 1 was defined as the base case which was a situation that did not change the ecosystem services (current situation). Alternative 2 and 3 were alternatives showing the better ecosystem service change. Alternative 2 was taken from the first level of 28 alternatives and alternative 3 was based on alternative 2, with a higher level of ecosystem service properties. Therefore, each interviewer was assigned with only 1 block (4 choice sets). The interviewees were requested to choose one alternative from one choice set for the best choice and one alternative from each choice set as exemplified in Figure 2.

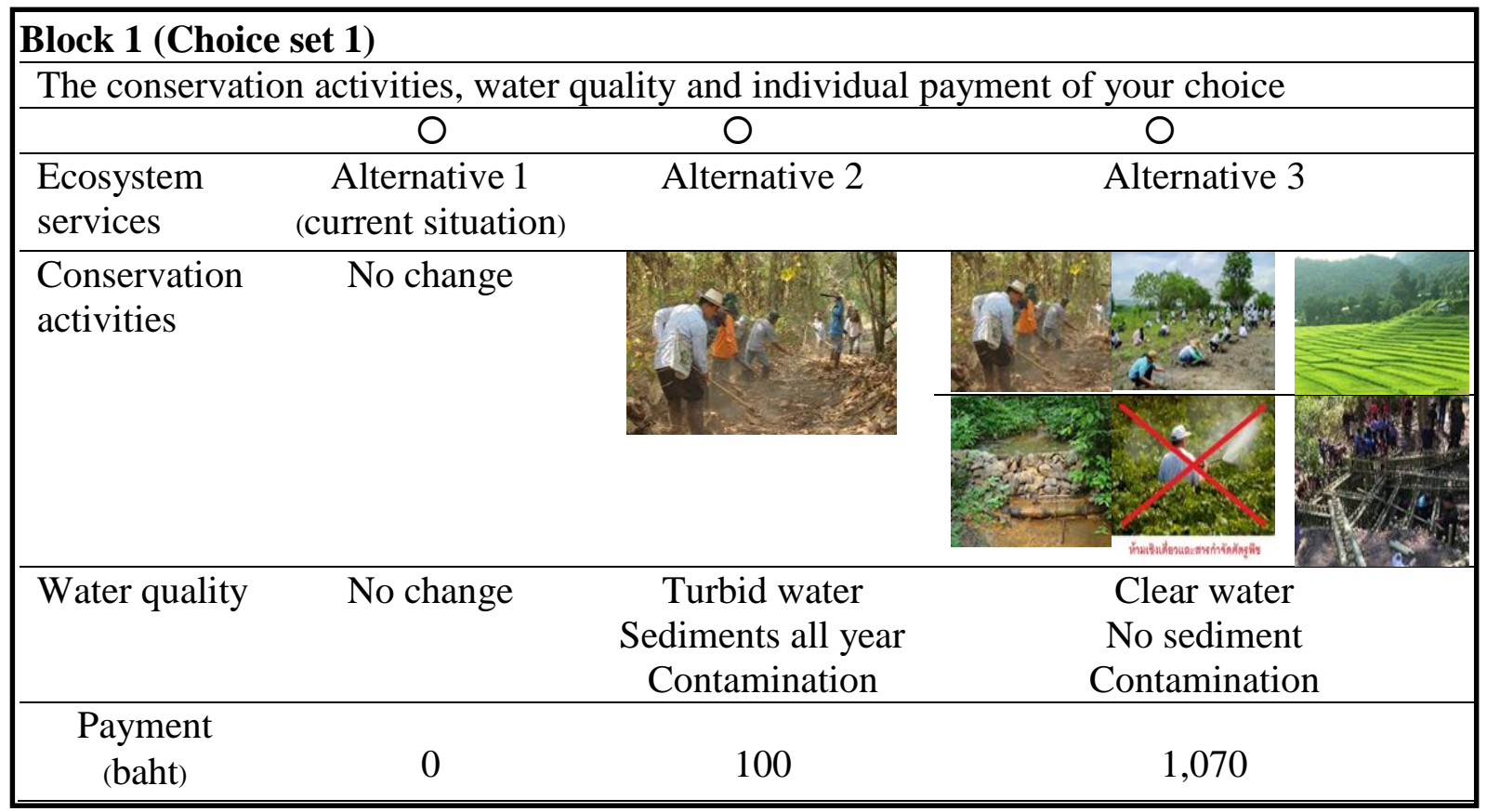

Figure 2. Sample of 1 choice set used in the interview. 
Conditional Logit model. The data about the water users' willingness to pay for improved water quality were analyzed by the conditional Logit model in Stata program as follows;

$$
\mathrm{V}_{\mathrm{ij}}=\beta_{1}+\beta_{2} \mathrm{~A}_{\mathrm{ik}}+\beta_{3} \mathrm{Q} 1_{\mathrm{ik}}+\beta_{4} \mathrm{Q} 2_{\mathrm{ik}}+\beta_{5} \mathrm{Q} 3_{\mathrm{ik}}+\beta_{6} \mathrm{Q}_{\mathrm{ik}}+\beta_{7} \mathrm{P}_{\mathrm{ik}}+\varepsilon_{\mathrm{i}}
$$

Where $\mathrm{V}_{\mathrm{ij}}$ is the indirect utility of the person $\mathrm{i}$ from the selection of alternative $\mathrm{j}$ represented by the independent variables as ecosystem service attributes, $A_{i k}$ is the number of conservation activities that the water users $i$ choose, $\mathrm{Q} 1_{\mathrm{ik}}$ is the water quality in level 1 that the water users i choose, $\mathrm{Q} 2_{\mathrm{ik}}$ is the water quality in level 2 that the water users i choose, $Q 3_{i k}$ is the water quality in level 3 that the water users $\mathrm{i}$ choose, $\mathrm{Q} 4_{\mathrm{ik}}$ is the water quality in level 4 that the water users $\mathrm{i}$ choose, $\mathrm{P}_{\mathrm{ik}}$ is the payment level $\mathrm{k}$ that the water users $\mathrm{i}$ choose, $\varepsilon_{\mathrm{i}}$ is a random error (average $=0$ ) and $\beta$ is the coefficient of attributes

Implicit prices. The implicit prices for a change in any attribute can be estimated using the results of the conditional as well as a nested Logit model in a linear form as follows;

$$
\mathrm{IP}=-\beta_{\text {Attribute }} / \beta_{\text {Payment }}
$$

Compensating surplus. The compensating surplus refers to the amount of additional money an agent would need to reach her initial utility after a change in prices, a change in product quality, or the introduction of new products. Compensating variation can be used to find the effect of a price change on an agent's net welfare (Hicks, 1939) expressed as;

$$
\mathrm{CS}=-\left(1 / \beta_{\text {Payment }}\right)\left(\mathrm{V}_{0}-\mathrm{V}_{1}\right)
$$

Damage cost of drought equation. Drought affects all parts of the environment and communities. Many different drought impacts are often grouped as environmental, social and economic impacts (National Drought Mitigation Center, 2017). The environmental impacts are the loss of plants' and animals' food and the destruction of wildlife habitat. The social impacts affect people's health and safety. Moreover, the economic impacts are impacts of drought that cost people (or business) money. There are a few different economic impacts of each sector as follows;

Agricultural sector: farmers may lose money from no cultivation and may have to spend more money on water supply or drought may destroy their crops.

Household sector: drought may affect their daily lives and households may lose their income or have to seek for water to use.

Business sector: businesses may lose income from stopping or decreasing services or may have to invest in the water supply. 
The equation was based on the drought damages between 2015 and 2017 following Logar et al. (2012). The damage cost of drought is calculated from the sum of damage cost (direct cost from drought such as loss of yield), prevention cost (cost for preventing drought such as buying the tank) and avoidance cost (cost from no cultivation). Moreover, the level of drought damage is also considered and classified into 4 levels, i.e., no effect (0), low effect (1), moderate effect (2) and high effect (3) and presented in percentage of sample and average cost.

Value of drought loss reduction $=$ Damage Cost + Prevention Cost + Avoidance Cost

This equation was developed to find out the total cost of drought damages in agricultural, household and business sectors in the watershed areas. It was adapted from intangible flood damage quantification (Lekuthai and Vongvisessomjai, 2001).

$$
\begin{aligned}
& D C A=\sum_{i=1}^{n} D A_{i} D Y_{i} P_{i}+\sum_{i=1}^{n} N_{i}\left(P_{i} E Y_{i}\right)-T V C_{i}+W+I \\
& D C H=\sum_{j=1}^{n} A F_{j} C_{j}+W+I \\
& D C B=\sum_{k=1}^{n} S F_{k} S D_{k} P_{k}+\sum_{k=1}^{n} S S_{k} P_{k}+W+I \\
& T D C=\sum_{l=1}^{4} A D C A_{l} P O p_{1 l}+A D C H_{l} P_{O o p_{2 l}}+A D C B_{l} P_{P p_{3 l}}
\end{aligned}
$$

Where DCA is the damage cost of agriculture (baht)

$\mathrm{DA}_{i} \quad$ is the damaged area of crop $i$ (rai)

$\mathrm{DY}_{i} \quad$ is the damaged yield of crop $i(\mathrm{~kg} / \mathrm{rai})$

$\mathrm{P}_{i} \quad$ is the price of crop $i$ (baht $/ \mathrm{kg}$ )

$\mathrm{N}_{i} \quad$ is the non-cultivated areas due to drought of crop $i$ (rai)

$\mathrm{EY}_{i} \quad$ is the expected yield when crop $i$ was cultivated (baht/rai)

$\mathrm{TVC}_{i} \quad$ is the total variable cost of crop $i$ (baht/rai)

$\mathrm{W}$ is the total value of additional water bought to solve the drought problem (baht)

I is the other investment cost to solve or prevent drought problem (baht)

$\mathrm{DCH} \quad$ is the damage cost of household (baht)

$\mathrm{AF}_{j} \quad$ is the number of days that activity $j$ got affected by drought (days)

$\mathrm{C}_{j} \quad$ is the opportunity cost of activity $j$ (baht/day)

$\mathrm{DCB}$ is the damage cost of business (baht)

$\mathrm{SF}_{k} \quad$ is the number of days that service $k$ got affected by drought (days) 
$\mathrm{SD}_{k} \quad$ is the decrease in service $k$ (person, room or table per day)

$\mathrm{P}_{k} \quad$ is the price of entry, room or average income of service $k$ (baht/person, room or table)

$\mathrm{SS}_{k} \quad$ is the number of days that service $k$ had to stop due to drought (days)

TDC is the total damage cost of drought (baht)

$\mathrm{ADCA}_{l}$ is the average damage cost of agriculture at the level $l, l$ is 1 , 2,3 or 4 (baht/farm)

$\mathrm{ADCH}_{l}$ is the average damage cost of households of level $l$ (baht/household)

$\mathrm{ADCB}_{l}$ is the average damage cost of business of level $l$ (baht/business)

$\operatorname{Pop}_{1 l, 2 l, 3 l}$ is the population of water user group 1 (agriculture), 2 (household) or 3 (business) that had drought effects at the level $l$ (household)

\section{RESULTS}

\section{Water users' willingness to pay for improved water quality}

The conditional Logit model was used when the base alternative of water quality had no change and the base alternative of payment was zero. The calculation from this model resulted in the indirect utility function from the change of attributes.

It was found that almost all attributes were statistically significant at the confidence level of $95 \%$. Implicit price or marginal value is the monetary value from the change of one attribute level, calculated from the coefficient of attributes and the coefficient of payment as shown in Table 2. The addition of 1 conservation activity could increase the marginal value to 91.56 baht/activity. The change from base situation to turbid water, sediments all year and chemical contamination could reduce the marginal value to -247.19 baht. The change from base situation to turbid water, sediments only in rainy season and chemical contamination could reduce the marginal value to -110.58 baht. The change from base situation to clear water, no sediments and chemical contamination could increase the marginal value to 29.15 baht. The change from base situation to clear water, no sediments and slight chemical contamination could increase the marginal value to 300.75 baht. The compensating surplus is the compensating payment from changing ecosystem services that the water users can get the same satisfaction or is the difference between the water users' willingness to pay and the price that consumers actually pay, as shown in Table 2 . 
Table 2. Implicit price and compensating surplus of attributes.

\begin{tabular}{lcc}
\hline \multicolumn{1}{c}{ Attributes } & $\begin{array}{c}\text { Implicit price } \\
\text { (baht) }\end{array}$ & $\begin{array}{c}\text { Compensating } \\
\text { surplus (baht) }\end{array}$ \\
\hline Conservation activities & 91.56 & 91.56 \\
$\begin{array}{l}\text { Turbid water, sediments all year and chemical } \\
\text { contamination }\end{array}$ & -247.19 & -219.31 \\
$\begin{array}{l}\text { Turbid water, sediments only in rainy season and } \\
\text { chemical contamination }\end{array}$ & -110.58 & -82.71 \\
$\begin{array}{l}\text { Clear water, no sediments, and chemical } \\
\text { contamination }\end{array}$ & 29.15 & 1.27 \\
$\begin{array}{l}\text { Clear water, no sediments, and slight chemical } \\
\text { contamination }\end{array}$ & 300.75 & 272.87 \\
\hline
\end{tabular}

From the Table 2, the addition of 1 conservation activity could increase the compensating surplus to 91.56 baht/activity. The change from base situation to turbid water, sediments all year and chemical contamination could reduce the compensating surplus to -219.31 baht. The change from base situation to turbid water, sediments only in rainy season and chemical contamination could reduce the compensating surplus to -82.71 baht. The change from base situation to clear water, no sediments and chemical contamination could increase the compensating surplus to 1.27 baht. The change from base situation to clear water, no sediments and slight chemical contamination could increase compensating surplus to 272.87 baht.

The alternatives that the water users were willing to pay were evaluated by representing the attributes and levels of attributes in the probability equation derived from the conditional Logit model. The result of this method was the probability for each alternative to be selected.

The top of alternatives selected by water users was alternative 16 with the probability of 0.2092511 . The marginal compensating surplus is used to evaluate the marginal willingness to pay for selected alternatives.

The marginal willingness to pay of each alternative can be used to evaluate the water users' willingness to pay per household. The willingness to pay was 459.07 baht/household.

The willingness to pay for water users per household can be used to evaluate the total willingness to pay for conserving natural resources and environment to improve water quality in Mae Sa watershed. The total willingness to pay was $9,098,308.33$ baht per year. 


\section{The analysis of socio-economic factors affecting the willingness to pay}

The Tobit model was used to estimate the maximum likelihood estimation (MLE) by setting the lower bound at 0 and the upper bound at 1 .

$\mathrm{WTP}=\mathrm{f}$ (Gender, Age, User, Income, Member, Source, Join, Frequency, Support)

Where: WTP is the indirect utility of the person $\mathrm{i}$ from the selection of alternative $\mathrm{j}$ represented by the independent variables as ecosystem service attributes

Gender is the gender of tourists ( 1 if male, 0 if female)

Age is the age of tourists (years)

User is the water user ( 1 if business, 0 if household)

Income is the water users' income per month (baht)

Member is the number of household members or business service users Source is the water source ( 1 if others, 0 if plumbing)

Join is having joined the conservation activities ( 1 if yes, 0 if never)

Frequency is the frequency of joining the conservation activities (time/year)

Support is support given to the conservation activities ( 1 if yes, 0 if no) i is a sample of $\mathrm{i}$

The analysis showed that the chi-square values were significant at 99 and 90 percent. There were 3 independent variables that influenced the willingness to pay of water users, which were income per month, participation in the conservation activities and support for the conservation activities.

Based on the coefficient and the marginal effect (Table 3), the increase of income per month by 100 baht could increase the willingness to pay by $0.034 \%$. The participation in and the support for the conservation activities could increase the willingness to pay by $0.106 \%$ and $1.00 \%$ respectively. Those samples ever participated in and supported for the conservation activities could increase their willingness to pay.

Table 3. The analysis of factors affecting the willingness to pay of users in Mae Sa watershed.

\begin{tabular}{lcccc}
\hline Variable & Coefficient & $\begin{array}{c}\text { Standard error } \\
\text { of coefficient }\end{array}$ & Marginal effect & $\begin{array}{c}\text { Standard error } \\
\text { of marginal } \\
\text { effect }\end{array}$ \\
\hline Gender & -0.0037135 & 0.0272757 & -0.00371 & 0.02726 \\
Age & -0.0007057 & 0.0010223 & -0.00071 & 0.00102 \\
User & 0.0102333 & 0.0532363 & 0.01023 & 0.05321 \\
Income & $0.0003386^{*}$ & 0.0001777 & $0.00034 *$ & 0.00018 \\
Member & -0.0003716 & 0.001063 & -0.00037 & 0.00106 \\
Source & -0.0518832 & 0.0395505 & -0.05186 & 0.03953 \\
Join & $0.1062635^{* * *}$ & 0.0384376 & $0.10622^{* * *}$ & 0.03842 \\
Frequency & -0.0018062 & 0.0081829 & -0.00181 & 0.00818 \\
Support & $1.009256^{* * *}$ & 0.1245056 & $1.00881^{* * *}$ & 0.12443 \\
\hline Nit: & & &
\end{tabular}

Note: $* * *, * *, *==>$ Significance at $1 \%, 5 \%, 10 \%$ level. 


\section{Damage cost of drought}

The impact of drought in the agricultural sector was calculated from 129 samples. Droughts during 2015 -2017 had effects at the different levels. Farmers in upstream areas got the highest effect in prevention, avoidance and damage costs with the average cost being 15,602, 28,432 and 45,520 baht/farm, respectively.

For the household sector, the damage costs of drought were presented in terms of preventing cost and damage cost from 230 samples. Households in downstream areas experienced the highest effect on the average from preventing and damage cost with 8,559 and 3,066 baht/household, respectively.

The drought seems to affect the business sector less than the agricultural sector as most business samples (74.79\%) did not get an effect from drought. Business sector had prevention, avoidance and damage cost with the average of $17,325,12,625$ and 13,111 baht/firm, respectively.

Finally, the percentages and average costs of each sector were used with the total population to calculate the total damage cost of droughts in Mae $\mathrm{Sa}$ watershed (Table 4).

Table 4. Total damage cost of drought in Mae Sa watershed during 2015-2017.

\begin{tabular}{|c|c|c|c|c|}
\hline \multirow[b]{2}{*}{ Type of water users } & \multicolumn{2}{|c|}{ Sample } & \multirow{2}{*}{$\begin{array}{c}\text { Total } \\
\text { population in } \\
\text { the watershed } \\
\text { in each sector }\end{array}$} & \multirow{2}{*}{$\begin{array}{c}\text { Total damage cos } \\
\text { of drought } \\
\text { (baht) }\end{array}$} \\
\hline & $\begin{array}{c}\% \text { of } \\
\text { total } \\
\text { samples } \\
\end{array}$ & $\begin{array}{c}\text { Average } \\
\text { damage cost } \\
\text { (baht/sample) }\end{array}$ & & \\
\hline \multicolumn{5}{|l|}{ Agriculture } \\
\hline - No effect & 67.44 & 0 & 871 & 0 \\
\hline - Low effect & 10.85 & 5,769 & 140 & 807,660 \\
\hline - Moderate effect & 13.17 & 15,279 & 168 & $2,566,872$ \\
\hline - High effect & 8.53 & 58,683 & 110 & $6,455,130$ \\
\hline Sum & 100.0 & 79,731 & 1,292 & $9,829,662$ \\
\hline \multicolumn{5}{|l|}{ Household } \\
\hline - No effect & 70.00 & 0 & 6,028 & 0 \\
\hline - Low effect & 8.26 & 815 & 711 & 579,465 \\
\hline - Moderate effect & 14.78 & 3,462 & 1,273 & $4,407,126$ \\
\hline - High effect & 6.96 & 23,947 & 599 & $14,344,253$ \\
\hline Sum & 100.0 & 27,701 & 8,611 & $19,330,844$ \\
\hline \multicolumn{5}{|l|}{ Business } \\
\hline - No effect & 74.36 & 0 & 163 & 0 \\
\hline - Low effect & 2.56 & 4,067 & 6 & 24,402 \\
\hline - Moderate effect & 11.54 & 12,379 & 25 & 309,475 \\
\hline - High effect & 11.54 & 52,242 & 25 & $1,306,050$ \\
\hline Sum & 100.0 & 68,688 & 219 & $1,639,927$ \\
\hline Sum of three sectors & 100.0 & 176,120 & 10,122 & $30,800,433$ \\
\hline \multicolumn{5}{|c|}{ The average cost of drought per } \\
\hline
\end{tabular}


The average damage cost of drought per sample is used to assess the total damage cost of drought in Mae Sa watershed. The results show that in the agricultural sector, there could be about 110 farmers experiencing an extreme effect of 58,683 baht/farm and the total damage cost of drought in this sector could be about 9,829,662 baht. For the household sector, 599 households possibly got an extreme effect of 23,947 baht/household and the total damage could cost about 19,586,717 baht. Whereas the business sector seems to get the lowest effect of drought in the watershed, only 56 from 219 businesses in the watershed possibly encountered the extreme effect of 52,242 baht/business and the total damage cost could be about 1,639,927 baht. The total damage cost of drought of all three sectors could be 30,800,433 baht. As the result, the damage cost of drought could be reduced up to 10,266,811 baht/year if the droughts in Mae Sa watershed can be prevented or reduced from supporting conservation activities to be done by the upstream villagers.

\section{DISCUSSION AND CONCLUSION}

This paper presents the ecosystem service valuation from the upstream conservation activities which affect water quality and water supply. These values are the partial economic value which actually contains the values of water, soil and forest. The economic values of water presented in terms of damage cost of drought loss reduction and the value of cleaned water. The damage cost of drought loss reduction was $10,266,811$ baht per year. It is assumed that conservation activities can prevent drought by $100 \%$. However, if the drought in the area can be prevented only $50 \%$, it is still considered high value. Moreover, these damage costs were calculated based on the last 3 years' information but the conversation activities in the upstream areas can have direct consequences for ecosystem services and last longer than 3 years. The total willingness to pay of water users in Mae Sa watershed was 9,098,308 baht. Thus, the economic value of water quality and quantity were 19,365,119 baht per year. The results from factors affecting the willingness to pay were the water users' income, the water users' ever participating in and supporting conservation activities whereas the latter two factors could increase their willingness to pay. This information can be used to implement PES in Mae Sa watershed by arranging a PES meeting forum and inviting all stakeholders to participate.

As the results of this study, the economic value can be used to present the benefits from ecosystem services to all stakeholders in the watershed to increase their awareness to conserve the natural resources and environment in the areas. Moreover, these economic values can be used as information for the downstream users to make a decision on payment in PES scheme for supporting the upstream villagers to increase their conservation activities. Therefore, the government should make the policy to generate PES continually. 


\section{REFERENCES}

Department of Water Resources. 2007. The Mae Sa basin. Baseline water resources storage in the area. Available from: http://www.water. go.th/basindata/maesa.index

Enters, T. 1995. The economics of land degradation and resource conservation in Northern Thailand. Institute of Southeast Asian Studies,Singapore: 90-110.

Federal Ministry for Economic Cooperation and Development: BMZ. 2012. Ecosystem service valuation approaches: the economics of desertification. land degradation and drought.

Hicks, J.R. 1939. Value and capital: An inquiry into some fundamental principles of economic theory. London: Clarendon Press.

Holmes, T.P., Adamowicz, W.L. 2003. Attribute-based methods. United States Department of Agriculture. Available from: https://www.fs.usda.gov/ treesearch/pubs/6313.

Land Development Department. 2005. Academic documents of the master plan for land use planning to prevent soil deterioration and increase the potential economic crops as well as soil and water conservation. Bangkok: Ministry of Agriculture and Cooperatives.

Lekuthai, A., Vongvisessomjai, S. 2001. Intangible flood damage quantification. Journal of Water Resources Management.15: 343-362. https://doi.org/10. 1023/A:1014489329348

Logar, I., and Van den Bergh, J.C.J.M. 2012. Damages and policies for drought mitigation and adaptation: review and recommendations. Water Resources Management: an International Journal. 27(6): 1707-1720. https://doi.org/ 10.1007/s11269-012-0119-9.

Mauerhofer, V., Hubacek, K., and Coleby, A. 2013. From polluter pays to provider gets: distribution of rights and costs under payments for ecosystem services. Ecology and Society. 18(4): 41. https:// doi.org/10. 5751/ES-06025-180441

Mae Rim Waterworks Office. 2017. Number of water users. Available from : https://www.pwa.co.th/province/branch/5510214

Meyerhoff, J.R., Liebe, U., and Hartje, V. 2008. Benefits of biodiversity enhancement of nature-oriented silviculture: evidence from two choice experiments in Germany. Journal of Forest Economics. 15: 37-58. https://doi.org/10.1016/j.jfe.2008.03.003

Millennium Ecosystem Assessment. 2005. Ecosystems and human well-being: synthesis. Washington, DC: Island Press.

Nantansen, G. 2008. The willingness to accept soil and water conservation of farmers in upper Mae Sa watershed, Chiang Mai province [master's thesis]. Department of Agricultural Economics, Faculty of Agriculture: Chiang Mai University. 
National Drought Mitigation Center. 2017. Types of drought impacts. Available from:http://drought.unl.edu/DroughtforKids/HowDoesDroughtAffectOu rLives/TypesofDroughtImpacts.aspx

National Statistics Office. 2005, 2012. Agricultural statistics of Thailand. Office of Agricultural Economics. Bangkok: Ministry for Agricultural and Cooperatives.

Pramoon, N. 2008. The willingness to pay for water supply of downstream farmers in Mae Sa watershed, Chiang Mai Province [master's thesis]. Department of Agriculture Economics: Chiang Mai University.

Pollution Control Department. 2011. Wastewater problems. Available from: http://www.pcd.go.th/info_serv/plan_strategy.html

Pong Yang and Mae Ram Sub-district Administrative Organization. 2016. Population Number.

Regional Environment Office 1. 2016. Ecological assessment: assessing condition and trend of ecosystem service of Mae sa watershed, Chiang Mai Province. The Completed report. p. 23-25.

Rungruangwong, W., and Prompati, S.G. 2007. River ecosystem monitoring. water quality and diversity of benthic animals. The Mae Sa River Doi Suthep-Pui National Park, Mae Rim District, Chiang Mai Province [Master's Thesis]. Faculty of Science: Chiang Mai University.

Steiner, F., Blair, J., Mcsherry, L., Guhathakurta, S., Marruffo, J., and Holm, M. 2000. A watershed at a watershed: the potential for environmentally sensitive area protection in the upper San Pedro Drainage Basin (Mexico and USA). Landscape and Urban Planning 49(3-4): 129 - 148. https://doi. org/10.1016/S0169-2046(00)00062-1

Stewart, S., and Kahn. J.R. 2006. An introduction to choice modeling for nonmarket valuation. In: Alberini, A., Kahn, J.R., Editors, Handbook on Contingent Valuation. Cheltenham: Edward Elgar.

Tongmee, A. 2007. Upland conservation and management: the report of biodiversity, forests and wildlife. Available from: http://chmthai. onep.go.th/chm/mountain/status/mana_utai.pdf.

USAID. 2014. Payment for ecosystem services pilot implementation in Mae Sa-Kog Ma Man and Bioshere Reserve. USAID Lowering Emissions in Asia's Forests (USAID LEAF).

Wunder, S. 2007. The efficiency of payments for environmental services in tropical conservation. Conservation Biology. 21(1): 48 - 58. https://doi. org/10.1111/j.1523-1739.2006.00559.x

Yamane, T. 1967. Statistics: an introductory analysis. $2^{\text {nd }}$ ed. New York: Harper and Row. 